\title{
MDA Framework Approach for Gamification-Based Elementary Mathematics Learning Design
}

\author{
Syahrizal Dwi Putra ${ }^{1 *}$, Verdi Yasin ${ }^{2}$ \\ ${ }^{1}$ Faculty of Computer Science, Esa Unggul University, Indonesia \\ ${ }^{2}$ Informatics engineering, STMIK Jayakarta, Indonesia \\ *Corresponding author E-mail: syahrizal.dwi@esaunggul.ac.id
}

Manuscript received 15 April 2021; revised 1 May 2021; accepted 15 June 2021. Date of publication 3 July 2021

\begin{abstract}
Mathematics is currently one of the compulsory subjects taught in schools and the most difficult subject. By using the MDA Framework approach based on gamification, a visual game of building space was designed. The MDA Framework consists of mechanics, namely certain rules which will then generate dynamics which are the result of the interaction of mechanics with players which will then automatically create aesthetics or player responses. From the design results, it is known that the visual game of building space has followed the stages in the MDA framework and has achieved its goal, namely to provide a learning process about the volume of space building.
\end{abstract}

Keywords: Gamification in Education, MDA Framework, Mathematics Learning Design.

\section{Introduction}

Today, technology and social networks are a big part of human life from an early age to a very old age. Children of all ages benefit directly or indirectly from developing technology. With the invention of Web 2.0 Technology, a large number of new websites, services, blogs and social networking platforms developed and are still emerging.

Mathematics is currently one of the compulsory subjects taught in Elementary Schools, Junior High Schools and Senior High Schools. In general, students think that mathematics is one of the most difficult subjects because students have to memorize formulas, follow examples of solving the problems given, and deliver subject matter that they feel is less interesting. In fact, on the other hand, mathematics is an important subject in human life, mathematics plays a role in almost all aspects even in today's technological and digital times. Today, mathematics contributes directly and fundamentally to business, finance, health and defense.

In studying mathematics, students think they must have a strong memory to memorize everything that exists formula. But what is needed is an understanding of a mathematical problem using the right formula. Now, almost every math textbook includes sample problems and solutions. It aims to enable students to understand the material they are learning. However, students tend to follow the solution of the questions given, so that when the questions given are slightly different from the examples given, students have difficulty solving them [1].

In Indonesia, the results of tests and evaluations in 2018 conducted by the Program for International Students Assessment (PISA) reported that of the total 12,098 students, Indonesia for mathematics with a score of 379 (decreased in 2015 the score for mathematics was 386). PISA states that Indonesia is still low in mastery of mathematics [2].

Over the last few years, gamification has emerged as a powerful technique that can be applied to a variety of problems to influence human behavior. Gamification initially appeared in the business and marketing sectors. Recently, gamification has begun to attract academics and educators [3]. Gamification in learning and education is a set of activities and processes to solve a problem related to learning and education by using or implementing a game mechanism [4]. Various gamification models have been proposed to increase students' motivation as reported by many studies. From the results of surveying 33 papers on gamification models in education that are applied in 4 application domains: generic, STEM, history, and language. The results of analyzing the proposed model using the MDA framework. The findings from the survey indicate that there are several representative gamification models that can be used as methods for increasing motivation, achievement and involvement in learning activities [5]. It is necessary to design elementary mathematics learning by using gamification in order to help students learn mathematics more interestingly. 


\section{Literature Review}

Article [6] presents an empirical study of published research on the application of gamification to education. Research is limited to papers that explicitly discuss the effects of using game elements in a particular educational context. These categories include gamification design principles, game mechanisms, the context of the application of gamification (type of application, level of education, and academic subjects), implementation, and evaluation. By mapping published works to classification criteria and analysing them, the study highlights the direction of current empirical research on the application of gamification to education.

In research [7], technology helps second language learning (English) with context used to reveal the impact of information and communication technology (ICT) in learning. Knowledge acquisition and testing are carried out with gamification training in the classroom. The test was first carried out with a written assessment, then carried out with gamification-assisted activity technology. The results showed that language teaching with ICT together with the context of gamification significantly increased language acquisition and awareness of the concept of peace. Furthermore, observations show that learning-assisted technology also minimizes children's distraction and enhances the learning curve.

Although no special attention is paid to motivating people to explore the topic of human judgment bias, a new process of using affordability for game experiences to engage the target audience called gamification is becoming increasingly popular. Gamification is used in various aspects of life, and is intensive in the field of education [8].

Based on the overall investigation, gamification has a positive effect on students' knowledge retention, regardless of age and gender [9]. The literature review on the adoption of gamification in education mainly mentions its positive effects on various behavioural and psychological outcomes [10].

\subsection{MDA Framework}

By definition, [11] the MDA framework describes each component as follows: 1) Mechanics: explain the rules and specific game components in terms of the actions that a player can perform or a process drive user action. 2) Dynamics: describes how the rules manifest during actual game play based on player input to the system as well as interactions between players. 3) Aesthetics: describes the desired emotional response generated by users when they interact with a gamified system.

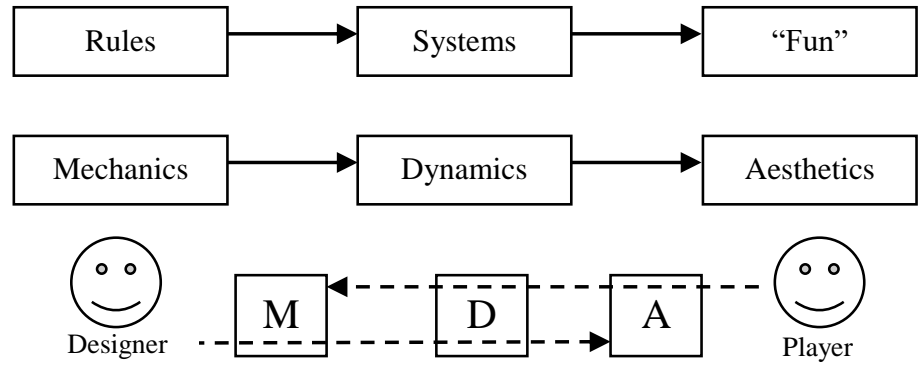

Fig. 1. MDA Framework

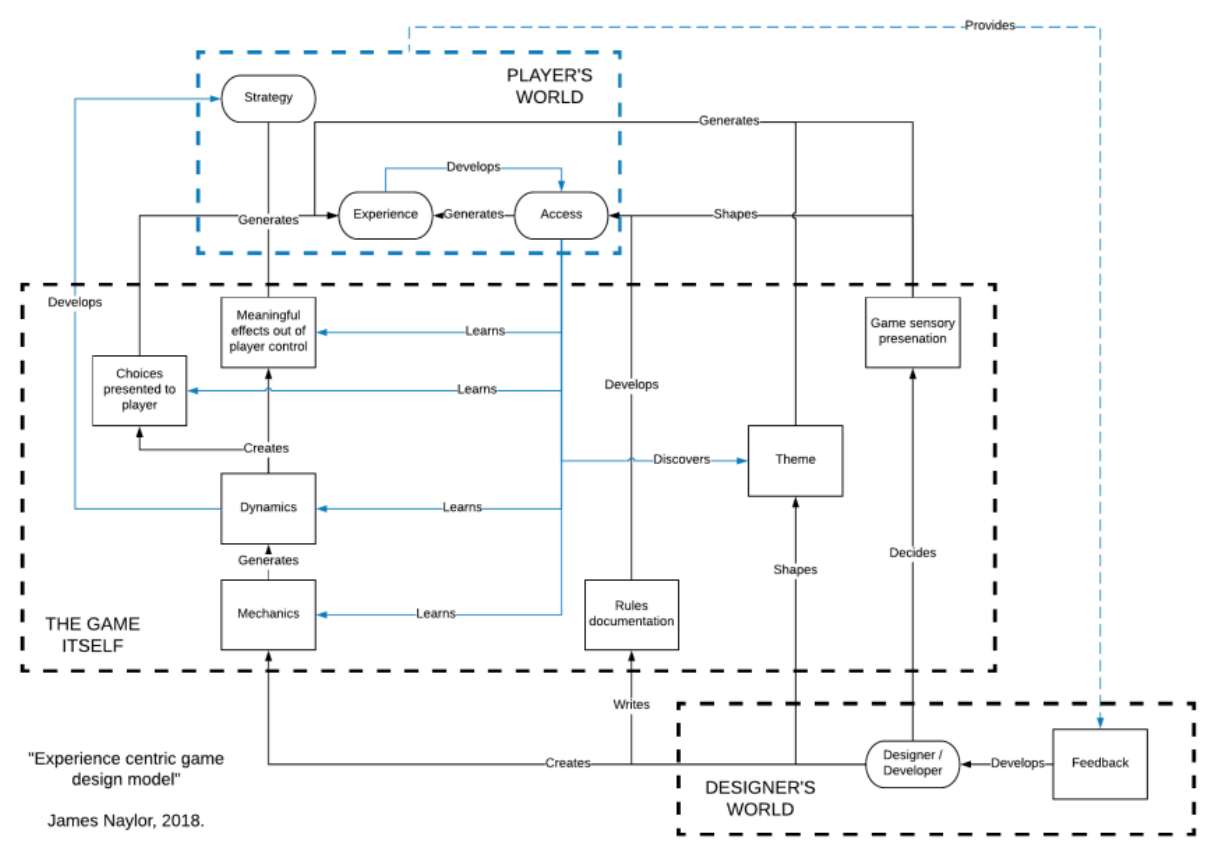

Fig. 2. A new model MDA Framework [12] 
As shown in Figure 3, a new model for game design: Moving beyond the "Mechanics, Dynamics, Aesthetics" framework. In this model there are 3 parts, namely: the player part, the game section itself and the designer section. In the designer section, the designer can create mechanics and generate dynamics from the feedback received from the player. The designer can also write rules and prepare the theme and code a sensory presentation game. On the player's part, the block strategy that deals with dynamics is used in a broad sense, namely a term that means the formulation of a practical approach by the player to consciously fulfill the game's objectives.

\section{Methods}

The research method used in this research is the literature review method by dissecting the definition of gamification and the MDA framework which can be used for elementary mathematics learning. The result is a elementary mathematics learning design based on the gamification-based MDA framework.

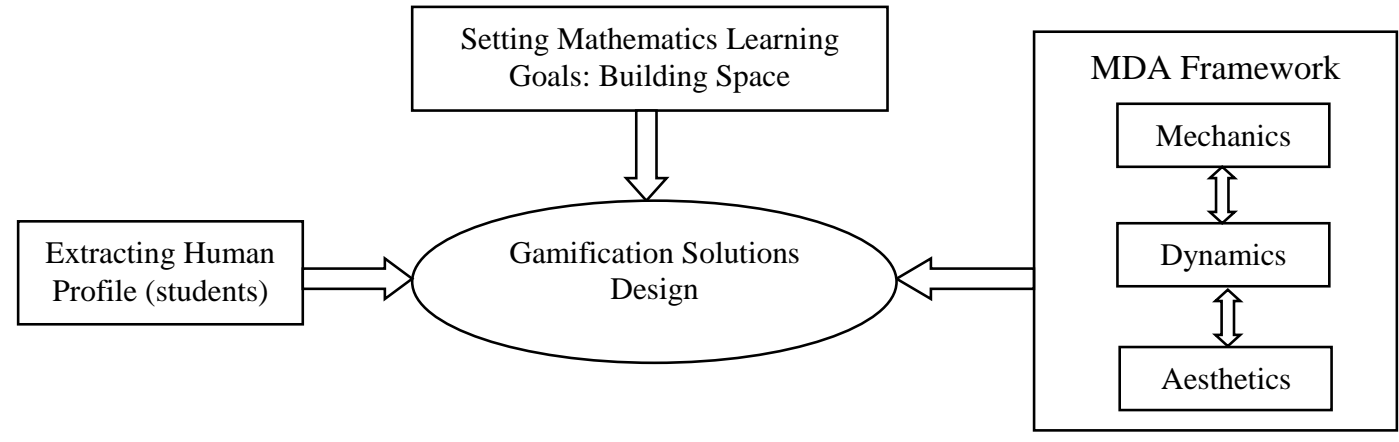

Fig. 3. The proposed model for gamification of elementary mathematics learning

As shown in Figure 1, the model includes 3 foundations. The first foundation is gamification seen from the perspective of the MDA framework and its role in gamification design. The second foundation is the feature of human resources in schools (students). The third is the learning objective.

\section{Results and Discussion}

The use of the MDA Framework for Primary School Mathematics Learning Design consists of 3 main components, namely, Mechanisms, Dynamics, and Aesthetics. From these three components, we can find out the aspects of the game, the flow of the game, and the experiences players get when playing the game.

\subsection{Mechanics}

In this case the mechanism in a game is a basic component that contains the rules of the game. This includes what the player does, algorithms, and data structures in the game. This component is made by a game designer and has concrete properties, where this component is able to make the player perform an action.

Thinking about the mechanics of the game for a game designer is important. The game must have a clear path and be able to encourage the player to be on the path that the game designer wants. At the basic stage of making this game, a game designer must work in detail so that the player makes the path. Some of the components in this mechanism are as follows:

1. Genres and Topics. The many types of game genres make this the first thing that must be determined when designing a game. The selected game genre is Role Playing Game (RPG). This game presents a gameplay that contains a leveling element. In this game, players will be free to explore the game world. Each character has different abilities and strengths and can even develop according to what the player wants.

2. Goals. In order for the game to be made clearer about the direction and purpose, it is necessary to think about the objectives of the game as well. For example, the game is made to improve the ability to remember the player or the goal is to introduce volume up space. With clear objectives, the resulting game will be maximized and information can be conveyed to players / students more clearly. The predetermined goals of the game will inevitably also affect the target audience of the game that will be designed later. For example, for the purpose of introducing the volume of building spaces, the main target audience is grade 5 elementary school students.

3. Platform. The choice of platforms for games is of course very diverse. Moreover, the development of technology today, causing an increasing number of choices of platforms that can be used for games to be designed. After knowing the genre and purpose of the game to be designed, we need to make a decision, which platform is suitable for the genre and purpose of the game. Because the choice of platform can also affect the success of the game.

4. Rating. The rating size can vary, it can also be adjusted to the purpose of the game and the target audience of the game being made. So that the game can be played as it should, not played by different age groups.

5. Level. There are also many types of leveling in a game, for example leveling in the form of numeric levels, where players must go to the next level by completing missions at the previous level. The levels in this game are in the form of a story route to get a happy ending. Selection of the route story that the player will determine the ending of the game being played. The route selection is determined in the order in which the player has visited. When a place is visited, the time in the game will change according to the conditions in each place. 


\subsection{Dynamics}

In this case dynamics can be described as gameplay. This component is the result of the interaction between the mechanism and the players in the game. The dynamics determine what happens to the player when the mechanism works.

If the mechanics cannot be seen by the player, but can lead the player to the right path of play, then it is different from the dynamics. The dynamics are part of the mechanism that can be seen by the player. It is like when a player presses a button or sends input to a game, so the results will be visible in real time. Some of the components in this mechanism are as follows:

1. Storyline. Every game has a storyline. This is intended to get players into the storyline of the game they are playing. In addition, the storyline also makes it easier for players to understand the intent and purpose of the game. Some games have unique storylines. With this unusual storyline, it will certainly attract the attention of players to play the game until the end because of the curiosity of what the end of the game will look like. This visual game of building space tells the story of someone who wants to look for various forms of building space. When someone has found a form of space, then he must answer the type of structure that space. After the type of shape is correct, information about the shape is displayed. Players will be given time to find answers to the questions asked.

2. Character. Apart from the unique story that is presented, there are also characters who are part of the sweetener in the game. The characters used in the game seem to be part of the player. With an attractive character design that is suitable, both with the genre and the target audience, it will add value to the game. Although characters in a game can be of added value, the use of characters in some games also has certain limitations. The characters in this game consist of main characters and supporting characters. The main character consists of the boy played by the player, as well as his female friends. The supporting characters in this game include residents who are met while searching for space.

3. Game Controls. Game control is also an important thing in a game. Sometimes there are games with interesting gameplay, beautiful characters, but game controls that are too complicated so that players get bored and give up. So, it needs to be designed so that game controls remain easy for players to do. The main controls in this game are using the mouse and keyboard.

4. Challenge. A game is not complete without a challenge. Challenges in the game are the main points that must be done by players. By completing challenges in the game players will get several benefits such as points, leveling up, and certain skills from the challenge. It is certain that every game has challenges that the player must complete.

5. Game Rules. In every game or game, of course, there are rules that must be carried out by the players. With these rules will help players to complete the mission to the end. So that the rules that are made must be clear and do not have a double meaning so that players can easily understand the meaning of the game rules.

\subsection{Aesthetics}

Aesthetics relates to the player's response to the dynamics of a game. Connect with the emotions that will be generated by the player when playing the game. The aesthetic is abstract and the emotional response that the player wants, where each player will have a different response to the game being played. Aesthetics has several components that will affect the game design that will be made, there are at least 5 components that we need to know as follows:

1. Sensation. A player's response to something completely foreign to them or a response to the player's senses. Like when a new player plays a game genre or game for the first time with complicated controls, this will affect the sensation they feel. Players / students will listen to background sounds and visual displays of attractive 2D and 3D spatial shapes so as to provide sensational responses to the five senses.

2. Narrative. The narrative here is an important component, because in this case the dramatization that develops from the plot will encourage the game to continue playing and find out the end of the game. Players can enjoy the story in the visual game of building space and the level of curiosity about the continuation of the story every time they complete one level.

3. Challenge. The challenge here is that players have a feeling of wanting to master something so that players have to do problem solving to the challenges they will face. Like in a game where the player completes a level, but he feels inadequate and continues to play the game to complete all the levels. Players can complete all the quiz questions in the visual game building space, complete routes and strategies to complete missions

4. Discovery. Discovery is usually driven by the player's need to explore the game scene. Players must explore the game scene to find the requested item in the game. So that player will find new things from the exploration he is doing.

5. Expression. The expression here is the player's creativity as a form of self-expression in the game. When players play, they will use their creativity to leave their mark. For example, some games require character creation or a custom character, at that stage the player will express himself by creating a character according to his wishes and imagination. In the visual game of building space, players claim they can choose a route to complete the game freely and choose what challenges they want to complete first.

\section{Conclusion}

The game of building space successfully implemented using MDA framework. This game also meets the criteria in the MDA Framework, namely 1) Mechanical (genres, goals, platform, rating, level), 2) Dynamics (storyline, character, game controls, challenges, game rules) and 3) Aesthetics (sensation, narrative), challenge, discovery, expression). The game of building space has been successfully accepted as a gamification that contains information and is educational for players regarding the introduction of spatial forms and volume calculations. 


\section{References}

[1] Y. Udjaja, V. S. Guizot, and N. Chandra, "Gamification for Elementary Mathematics Learning in Indonesia," Int. J. Electr. Comput. Eng., vol. 8, no. 5, p. 3860, 2018

[2] OECD, "Programme for international student assessment (PISA) results from PISA 2018.," Oecd, pp. 1-10, 2019.

[3] M. M. Alhammad and A. M. Moreno, "Gamification in software engineering education: A systematic mapping," J. Syst. Softw., vol. 141, pp. 131-150, 2018.

[4] S. Kim, K. Song, B. Lockee, and J. Burton, Advances in Game-Based Learning Gamification in Learning and Education Enjoy Learning Like Gaming. 2018.

[5] G. P. Kusuma, E. K. Wigati, Y. Utomo, and L. K. Putera Suryapranata, "Analysis of Gamification Models in Education Using MDA Framework," Procedia Comput. Sci., vol. 135, pp. 385-392, 2018.

[6] Y. Atif and C. Chou, "International Forum of Educational Technology \& Society Digital Citizenship Innovations in Education , Practice, and Pedagogy Published by: International Forum of Educational Technology \& Society Linked references are available on JSTOR for this article," J. Educ. Technol. Soc., vol. 21, no. 1, pp. 152-154, 2018.

[7] D. Kayimbaşioğlu, B. Oktekin, and H. Haci, "Integration of Gamification Technology in Education," Procedia Comput. Sci., vol. 102, no. August, pp. 668-676, 2016.

[8] J. H. Nikoletta-Zampeta Legaki, Kostas Karpouzis, Vassilios Assimakopoulos, "Gamification to avoid cognitive biases: An experiment of gamifying a forecasting course," Technol. Forecast. Soc. Change, vol. 167, 2021.

[9] L. M. Putz, F. Hofbauer, and H. Treiblmaier, "Can gamification help to improve education? Findings from a longitudinal study," Comput. Human Behav., vol. 110, no. April, p. 106392, 2020.

[10] B. Osatuyi, T. Osatuyi, and R. De La Rosa, "Systematic review of gamification research in is education: A multi-method approach," Commun. Assoc. Inf. Syst., vol. 42, no. 1, pp. 95-124, 2018.

[11] F. Marisa, T. M. Akhriza, A. L. Maukar, A. R. Wardhani, S. W. Iriananda, and M. Andarwati, "Gamifikasi (Gamification) Konsep dan Penerapan," JOINTECS (Journal Inf. Technol. Comput. Sci., vol. 5, no. 3, p. 219, 2020.

[12] J. Naylor, "A new model for game design: Moving beyond the 'Mechanics, Dynamics, Aesthetics' framework," naylorgames.com, 2018. [Online]. Available: https://naylorgames.com/2018/06/21/a-new-model-for-game-design-moving-beyond-the-mechanicsdynamics-aesthetics-framework/. [Accessed: 15-May-2021]. 